\title{
The role of L-carnitine in acetyl salicylic acid-induced acute gastric mucosal injury in rats
}

\author{
Burak Uz ${ }^{1}$, Cansel Turkay ${ }^{2}$, Mehtap Erkmen Uyar ${ }^{1}$, Mehmet Erol Yildirim ${ }^{3}$, Semsettin Sahin ${ }^{4}$, \\ Hacer Haltas 5 , Timucin Aydogan², Efkan Uz
}

\begin{abstract}
${ }^{1}$ Department of Internal Medicine, Faculty of Medicine, Fatih University, Ankara, Turkey ${ }^{2}$ Department of Gastroenterology, Faculty of Medicine, Fatih University, Ankara, Turkey ${ }^{3}$ Department of Urology, Faculty of Medicine, Fatih University, Ankara, Turkey

${ }^{4}$ Department of Biochemistry, Faculty of Medicine, Gaziosmanpasa University, Tokat, Turkey

${ }^{5}$ Department of Pathology, Faculty of Medicine, Fatih University, Ankara, Turkey

${ }^{6}$ Department of Medical Biochemistry, Faculty of Medicine, Suleyman Demirel

University, Isparta, Turkey
\end{abstract}

Submitted: 16 December 2016

Accepted: 7 February 2017

Arch Med Sci Civil Dis 2017; 2: e1-e10

DOI: https://doi.org/10.5114/amscd.2017.66354

Copyright @ 2017 Termedia \& Banach

\section{Abstract}

Introduction: The aim of this study was to determine the protective effects of L-carnitine on acetyl salicylic acid (ASA)-induced acute gastric mucosal injury through oxidant/antioxidant parameters and histopathological alterations in rat gastric tissues.

Material and methods: Forty-two rats were randomly assigned to six groups: The control group received $1 \mathrm{mg} / \mathrm{kg}$ distilled water, while the other groups were pretreated with L-carnitine $50 \mathrm{mg} / \mathrm{kg} /$ day $(\mathrm{LC})$, pantoprazole $40 \mathrm{mg} /$ $\mathrm{kg} /$ day (PPI), ASA + LC (50 mg/kg/day), and ASA + PPI (40 mg/kg/day), for 21 days, respectively. On day 23 , gastric mucosal injury was induced by a single intragastric administration of $600 \mathrm{mg} / \mathrm{kg}$ aspirin in ASA, ASA + LC, and ASA + PPI groups. The animals were killed 60 min after the administration of aspirin. The stomach of each animal was removed. Gastric mucosal injury was scored histopathologically (ulcer score). Tissue catalase (CAT), glutathione peroxidase (GSH-Px), and superoxide dismutase (SOD) activities, and malondialdehyde (MDA) and nitric oxide (NO) levels were also measured.

Results: The ulcer score increased significantly in the ASA group, but this increase was not significantly inhibited by the administration of L-carnitine $(2.71 \pm 1.0$ vs. $2.57 \pm 0.5, p=0.965)$. The CAT and GSH-Px activities were significantly reduced, whereas MDA and NO levels were significantly increased in the ASA group. Pretreatment with L-carnitine did not alter CAT or GSH-Px activities, but reduced MDA and NO levels insignificantly $(p=0.204$ and $p=0.277$, respectively).

Conclusions: Long-term administration of L-carnitine did not improve the oxidative and histological parameters of acute gastric mucosal injury induced by ASA.

Key words: lipid peroxidation, L-carnitine, oxidative injury, acetyl salicylic acid, anti-oxidant.

\section{Introduction}

Acetyl salicylic acid (ASA) is a potent non-steroidal anti-inflammatory drug (NSAID) used for the treatment of rheumatological disorders and more recently primary and secondary prevention of cardiovascular

\author{
Corresponding author: \\ Burak Uz MD \\ Department of \\ Internal Medicine \\ Faculty of Medicine \\ Fatih University \\ Ankara, Turkey \\ Phone: +90 3122026317 \\ E-mail: burakuz78@gmail. \\ com
}


events. The main concern regarding the use of aspirin is the potential for developing serious gastrointestinal (GI) events, such as Gl bleeding [1]. Accumulating information indicates that reactive oxygen species (ROS) and oxidative injury might be possible underlying factors in the pathogenesis of mucosal injury [2]. Upper GI injury from ethanol [3], ischemia/reperfusion [4], Helicobacter pylori [5], and stress [6] can all be linked to an ROS-producing mechanism. The GI tract has the capability to produce large amounts of ROS via mucosal oxidases found in resident leukocytes of the lamina propria [7]. Physiologic antioxidant systems against these detrimental factors include antioxidant enzymes, such as catalase (CAT), superoxide dismutase (SOD), and glutathione peroxidase (GSH-Px), and free-radical scavengers. A few, such as carnosine, glutathione, and uric acid, are synthesized by living cells, whereas most others are derived from food [8]. Therefore, the imbalance between the detrimental and defensive factors appears to be critical in the development of mucosal lesions in the GI tract.

Carnitine is a hydrophilic molecule that plays an essential role in the transfer of long-chain fatty acids across the inner mitochondrial membrane in which $\beta$-oxidation occurs via the citric acid cycle [9], and therefore it has been used to treat organic acidemias [10]. It was first characterized in muscle extracts in 1905 and named from the Latin carnis (flesh) [11]. The chemical structure later was shown to be 3-hydroxy-4-(N-trimethylammonio) butanoate [12], and in 1962, the biologically active form of carnitine was identified as the $L(-)$ stereoisomer, or levocarnitine [13]. L-carnitine is also endogenously synthesized from trimethyllysine (using the essential amino acids lysine and methionine) in humans at a rate of $1-2 \mathrm{~mol} / \mathrm{kg} /$ day $[13,14]$. The enzyme responsible for the hydroxylation required in the last step of synthesis is only present in human kidney, liver, and brain [9]. Given its essential role in metabolism, L-carnitine plasma and tissue levels are maintained within a narrow homeostatic range that is controlled by $\mathrm{Gl}$ absorption, endogenous biosynthesis, renal tubular reabsorption, and compartmentalization through carrier-mediated transport between plasma and tissues $[14,15]$.

Though the therapeutic benefits of L-carnitine and its ester congeners have yet to be clarified, they have exhibited many pharmacological effects. Carnitine therapy has been used to treat patients with heart failure; typical benefits include improved exercise capacity and peak oxygen consumption, reduced fatigue, and improved muscle conditioning [16]. Carnitine also shows potential benefits in the management of other cardiovascular diseases, including peripheral vascular disease, congestive heart failure, angina, cardiac arrhyth- mias, and anthracycline-induced cardiotoxicity $[17,18]$. Studies also reported beneficial effects of L-carnitine on skeletal muscle functions, including reduced muscle cramps, improved exercise capacity, increased muscle strength and mass, decreased asthenia and dyspnea, and increased peak oxygen consumption [19].

It is known that L-carnitine and its derivatives prevent the formation of ROS, scavenge free radicals, and protect cells from peroxidative stress [2024]. The beneficial effects of L-carnitine on ethanoland stress-induced gastric mucosal injury in rats have been shown by several experimental studies $[21,25]$. Among NSAIDs, L-carnitine was used in an indomethacin-induced gastric injury preliminary rat model and found to be effective [26]. However, no study has been reported for ASA-induced gastric mucosal injury despite its worldwide usage.

Therefore, it was reasonable to hypothesize that L-carnitine might provide protection against ASA-induced gastric mucosal injury. The aim of the present study was to assess the possible gastroprotective effect(s) of L-carnitine in a rat model of ASA-induced gastric mucosal injury and to elicit the potential underlying mechanisms. For this purpose, we studied the role of L-carnitine in oxidative stress by measuring alterations in CAT, GSH-Px and SOD activities. We also evaluated malondialdehyde (MDA) level as a marker of lipid peroxidation and nitric oxide (NO) level for endothelial functions. In addition, gastric mucosal injury was scored histopathologically for each sample (histological ulcer score).

\section{Material and methods}

\section{Chemicals and drugs}

L-carnitine (SIC0283-5G, L-carnitine hydrochloride, synthetic, $\geq 98 \%$ ), $\beta$-nicotinamide adenine dinucleotide phosphate, and glutathione reductase were purchased from Sigma Chemical (St Louis, MO, USA). Chloroform, ethanol absolute, trichloroacetic acid, hydrochloric acid, sulfanilamide, Folin-Ciocalteu's phenol reagent, glutathione reduced and 2,4-dinitrophenylhydrazine were all purchased from Merck (Darmstadt, Germany). Pantoprazole (Pantpas $40 \mathrm{mg}$ ) was obtained from Bayer, and ASA (Asinpirine $300 \mathrm{mg}$ ) was obtained from Ibrahim Etem Ulagay.

\section{Animals}

The study protocol was approved by the Local Animal Care and Use Committee with the project number P-53010801-1. All animal experiments were carried out in accordance with the National Institutes of Health Guide for the Care and Use of Laboratory Animals (NIH Publications No. 80-23, revised 1978). Forty-two male Wistar albino rats, 
each weighing about 250-280 g, were used. The animals were housed at $22 \pm 1^{\circ} \mathrm{C}$ on a 12 -h daynight regimen and received a standard diet and water ad libitum.

\section{Experimental design}

The rats were randomly allocated to six groups, each consisting of 7 rats, with different pretreatments as follows: group 1 (control), $1 \mathrm{ml}$ distilled water was given orally to control rats by intragastric gavage for 21 days; group 2 (ASA) received a standard diet and water ad libitum for 21 days (similar as in all study groups), and subsequently received ASA $600 \mathrm{mg} / \mathrm{kg}$ by intragastric gavage after 36-hour fasting (on day 23); group 3 (LC), L-carnitine $50 \mathrm{mg} / \mathrm{kg} /$ day was suspended with $1 \mathrm{ml}$ of $0.9 \% \mathrm{NaCl}$ and was administered by intragastric gavage to the rats for 21 days; group 4 (PPI), rats were treated with pantoprazole $40 \mathrm{mg} / \mathrm{kg}$ / day by intragastric gavage for 21 days; group 5 $(A S A+L C)$, the rats were pretreated with L-carnitine $50 \mathrm{mg} / \mathrm{kg} /$ day for 21 days, followed by a single intragastric $600 \mathrm{mg} / \mathrm{kg}$ ASA administration after 36-hour fasting (in day 23); and finally group 6 (ASA + PPI), pantoprazole $40 \mathrm{mg} / \mathrm{kg} /$ day was administered for 21 days, and subsequently the animals were given ASA $600 \mathrm{mg} / \mathrm{kg}$ by intragastric gavage after 36-hour fasting (on day 23).

On day 22, all animals were deprived of food for $36 \mathrm{~h}$ prior to the experiments, but were allowed free access to water. Before the administration of ASA, the rats in groups 3 and 5 were treated with a single high dose of L-carnitine ( $375 \mathrm{mg} / \mathrm{kg}$ ), and groups 4 and 6 were treated with pantoprazole $40 \mathrm{mg} / \mathrm{kg}$. ASA at a single dose of $600 \mathrm{mg} / \mathrm{kg}$ was administered by intragastric gavage to group 2 . The rats in groups 5 and 6 were subjected to ASA in the same manner as in group 2. At the end of the experimental period, and $60 \mathrm{~min}$ after the administration of ASA, all animals were anesthetized intraperitoneally with ketamine hydrochloride $(75 \mathrm{mg} / \mathrm{kg})$ and xylazine $(8 \mathrm{mg} / \mathrm{kg})$ and their abdomens were opened by a midline incision. The stomachs were excised rapidly, and cut along the greater curvature. The gastric tissues were gently rinsed under tap water to remove gastric contents and/or blood concomitant (if so); otherwise they were washed in a physiological saline bath. The stomachs were divided into two sections. One part was separated, immediately frozen in liquid nitrogen, and then stored at $-80^{\circ} \mathrm{C}$ until the analysis time used for further enzymatic analysis, whereas the other part was stored in $10 \%$ formalin for histopathological examination.

\section{Histopathological evaluations}

After fixation in $10 \%$ formalin solution, samples were processed, embedded in paraffin and sectioned at $4 \mu \mathrm{m}$ by a microtome. Then, sections were deparaffinized, rehydrated and stained with hematoxylin-eosin ( $\mathrm{HE})$. The lesions were counted and evaluated with a light microscope by an observer who was blinded to the treatment. Gastric damage was scored for each histological section on a 0-6 scale as follows [27]: score 0 - no lesion; score 1 - diffuse hyperemia; score 2 - one or two hemorrhagic lesions; score 3 - three to five hemorrhagic lesions or erosions; score 4 - more than five hemorrhagic lesions or erosions; score $5-20$ to $40 \%$ of total gastric surface with hemorrhagic lesions or multiple erosions; score 6 - more than $40 \%$ of total gastric surface with hemorrhagic lesions or multiple erosions.

\section{Assessment of enzymatic activities}

After weighing the sample tissues, they were homogenized in ten volumes of ice-cold tris- $\mathrm{HCl}$ buffer (0.2 mM, pH 7.4); homogenization (homogenizer: IKA Ultra-Turrax t 25 Basic, Germany) was carried out for $2 \mathrm{~min}$ at $13000 \mathrm{rpm}$. All procedures were performed at $4^{\circ} \mathrm{C}$. Homogenate, supernatant and extracted samples were prepared and the following determinations were made on the samples.

\section{Measurement of SOD activity}

Total (Cu, Zn, Mn) SOD activities were determined according to the method of Sun et al. [28]. The principle of the method is based on the inhibition of nitroblue tetrazolium (NBT) reduction by the xanthine-xanthine oxidase system as a superoxide generator. Activity was assessed in the ethanol phase of the supernatant after $1.0 \mathrm{ml}$ of ethanol-chloroform mixture $(5: 3, \mathrm{v} / \mathrm{v})$ was added to the same volume of sample and centrifuged. One unit of SOD was defined as the amount causing $50 \%$ inhibition of the NBT reduction rate. The SOD activity is expressed as $\mathrm{U} / \mathrm{mg}$ protein.

\section{Measurement of CAT activity}

The CAT activity was determined according to Aebi's method [29]. The principle of the method is based on the determination of the rate constant $\left(\mathrm{s}^{-1}, \mathrm{k}\right)$ of the $\mathrm{H}_{2} \mathrm{O}_{2}$ decomposition rate at $240 \mathrm{~nm}$. Results are expressed as $\mathrm{kg}^{-1}$ protein.

\section{Measurement of GSH-Px activity}

The GSH-Px activity was measured by the method of Paglia and Valentine [30]. The enzymatic reaction in the tube containing NADPH, reduced glutathione (GSH), sodium azide and glutathione reductase was initiated by addition of $\mathrm{H}_{2} \mathrm{O}_{2}$, and the change in absorbance at $340 \mathrm{~nm}$ was monitored by a spectrophotometer (Shimadzu UV1700 , Japan). Activity is expressed as U/g protein. 


\section{Determination of MDA}

The MDA levels were determined by the double heating method of Draper and Hadley [31]. The principle of the method is the spectrophotometric measurement of the color generated by the reaction of thiobarbituric acid (TBA) with MDA. For this purpose, $2.5 \mathrm{ml}$ of $100 \mathrm{~g} / \mathrm{l}$ trichloroacetic acid solution was added to $0.5 \mathrm{ml}$ of homogenate in each centrifuge tube and the tubes were placed in a boiling water bath for 15 min. After cooling in tap water, the tubes were centrifuged at $1000 \mathrm{xg}$ for $10 \mathrm{~min}, 2 \mathrm{ml}$ of the supernatant was added to $1 \mathrm{ml}$ of $6.7 \mathrm{~g} / \mathrm{l}$ TBA solution in a test tube, and the tube was placed in a boiling water bath for $15 \mathrm{~min}$. The solution was then cooled in tap water and its absorbance was measured using a spectrophotometer at $532 \mathrm{~nm}$. The levels of MDA were calculated by the absorbance co-efficient of the MDA-TBA complex (absorbance co-efficient $=1.56$ $\left.\times 10^{5} \mathrm{~cm}^{-1} \mathrm{M}^{-1}\right)$ and are expressed as nanomoles per gram $(\mathrm{nmol} / \mathrm{g})$ of protein. Protein concentration was determined with the Lowry method [32].

\section{Measurement of NO level of gastric mucosa}

Measurement of NO is very difficult in biological specimens; therefore tissue nitrite $\left(\mathrm{NO}_{2}^{-}\right)$and nitrate $\left(\mathrm{NO}_{3}^{-}\right)$were estimated as an index of $\mathrm{NO}$ production. Samples were initially deproteinized with Somogi reagent. Total nitrite (nitrite + nitrate) was measured after conversion of nitrate to nitrite by copperized cadmium granules by a spectrophotometer at $545 \mathrm{~nm}$. A standard curve was established with a set of serial dilutions $\left(10^{-8}-10^{-3}\right.$ $\mathrm{mol} / \mathrm{l}$ ) of sodium nitrite. Linear regression was carried out using the peak area from the nitrite standard. The resulting equation was then used to calculate the unknown sample concentrations. Results were expressed as micromoles per gram ( $\mu \mathrm{mol} / \mathrm{g})$ of protein [33].

\section{Statistical analysis}

Data analysis was carried out with SPSS (Statistical Package for Social Sciences, SPSS Inc., Chicago, IL, United States) 11.5 Windows program package. The Shapiro-Wilk test was used to evaluate whether the distribution of continuous variables was normal or not. Descriptive statistics were presented as the mean \pm standard error of mean or median \pm interquartile range for continuous variables, and presented as number of cases and (\%) percentage for nominal variables. The one-way analysis of variance (one-way ANOVA) was used to assess statistical significance of differences between groups for normally distributed continuous variables, and the Kruskal-Wallis test was used in order to assess for non-normally distributed continuous variables. Post-hoc Tukey or Kruskal-Wallis multiple comparison tests were used respectively to determine the group/groups which cause significant differences with ANOVA or Kruskal-Wallis analyses. A p-value of less than 0.05 was considered to be statistically significant.

\section{Results}

\section{Effect of L-carnitine on ASA-induced acute gastric mucosal injury}

In contrast to the normal color and appearance of the gastric mucosa in control, PPI and LC group rats (Figure $1 \mathrm{~A}-\mathrm{C}$ ), the mucosa of rats exposed to ASA lost its integrity, and petechial bleeding and erosions were detected (Figure $1 \mathrm{D})$. The histopathological gastric injury score (ulcer score) increased significantly $1 \mathrm{~h}$ after the administration of ASA (Table I). This increase was not significantly inhibited by the treatment with PPI (Table I and Figure $1 \mathrm{E}$ ), nor was it significantly reduced by L-carnitine treatment (Table I and Figure $1 \mathrm{~F}$ ).

The histopathological ulcer scores of the study groups are depicted in Table I. Ulcer scores of control, PPI and LC groups were similar. The ulcer score of the ASA group was significantly higher than control, LC and PPI groups ( $p<0.001, p<0.001$, and $p<0.001$, respectively). The ulcer score of the ASA + PPI group was lower than that of the ASA group, but the difference was not significant $(p=0.081)$. Pretreatment of rats with L-carnitine (ASA $+\mathrm{LC}$ group) did not reduce the ulcer index compared to the animals that received ASA alone (ASA group) $(p=0.965)$.

\section{Activity of gastric antioxidant enzymes}

\section{Catalase activity}

Catalase activity was significantly reduced after the administration of acetyl salicylic acid in the ASA group compared to controls $(p=0.028)$. A borderline decline in catalase activity was detected in LC and PPI groups compared to the control group ( $p=0.057, p=0.051$, respectively). Pretreatment with PPI (ASA + PPI) or L-carnitine (ASA $+\mathrm{LC})$ did not alter the catalase activity compared to the ASA group ( $p=0.927, p=1.00$, respectively) (Table II and Figure 2).

\section{SOD activity}

There was no significant difference between study groups in terms of SOD activity (Table II).

\section{GSH-Px activity}

The GSH-Px activity was significantly reduced after the administration of ASA and L-carnitine ( $p=0.001, p=0.028$, respectively), but PPI administration did not alter GSH-Px activity significantly ( $p=0.143)$ compared to controls. Pretreatment 
A
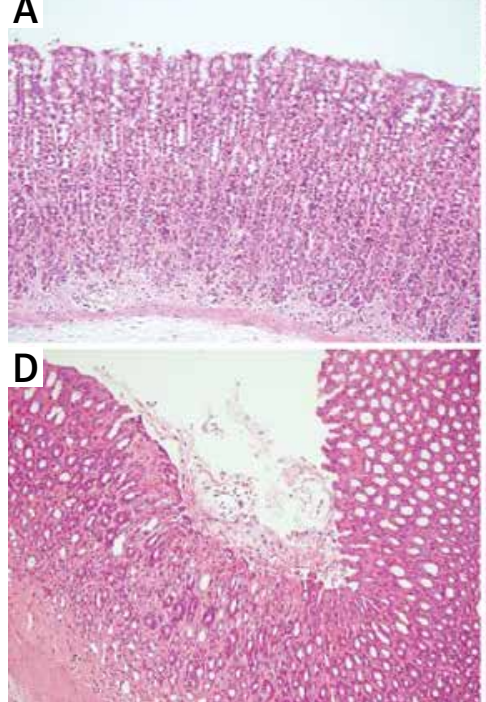

B

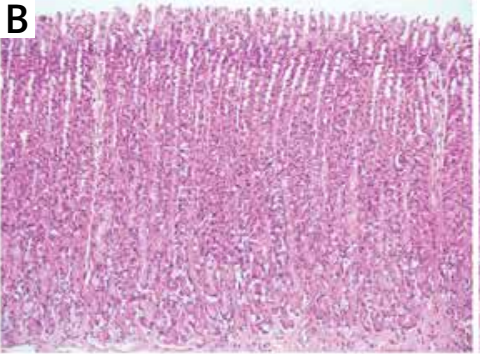

$E$

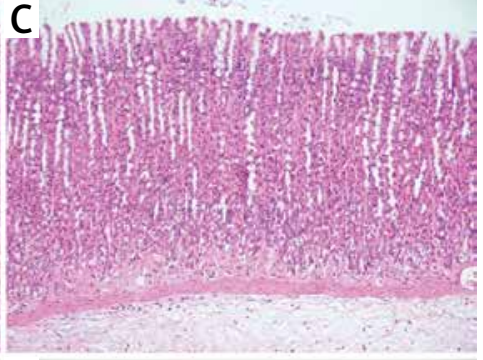

F
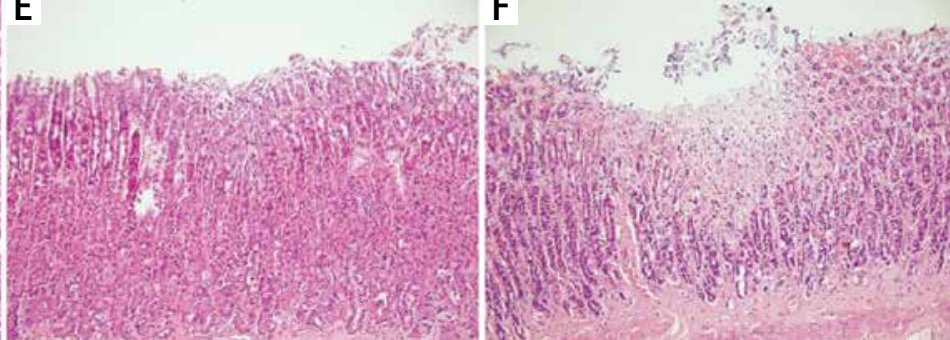

Figure 1. A - Normal appearance of gastric mucosa in control group of rats, HE 200x. B - Normal appearance of gastric mucosa in proton-pump inhibitor (PPI) group of rats, HE 200x. C - Normal appearance of gastric mucosa in L-carnitine (LC) group of rats, HE 200x. D - Hemorrhagic mucosal erosions and inflammatory cell infiltrations developed in the glandular stomach of rats $1 \mathrm{~h}$ after the administration of acetyl salicylic acid (ASA), HE 200x. E - The administration of PPI at a dose of $40 \mathrm{mg} / \mathrm{kg}$ macroscopically reduced these hemorrhagic erosions and edematous lesions (ASA + PPI), HE 200x. F - The administration of L-carnitine did not reduce the hemorrhagic erosions and edematous lesions (ASA + LC), HE 200x

with PPI (ASA + PPI) and pretreatment with L-carnitine (ASA + LC) did not alter GSH-Px activity significantly compared to the animals that received only ASA ( $p=0.279, p=0.995$, respectively) (Table II and Figure 3).

\section{Lipid peroxidation in gastric tissue}

\section{MDA levels}

The MDA levels were significantly increased in rats that received ASA alone compared to controls $(p=0.003)$. Administering L-carnitine alone did not alter the MDA levels ( $p=0.967)$. Pretreatment with PPI (ASA + PPI) significantly reduced MDA levels $(p<0.001)$, whereas pretreatment with L-carnitine $(A S A+L C)$ reduced MDA levels insignificant-
Table I. Histopathological scoring of the study groups

\begin{tabular}{|lccc|}
\hline Group & $N$ & Ulcerated animal & Ulcer score \\
\hline Control & 7 & $0 / 7$ & $0.14 \pm 0.4^{* *}$ \\
\hline PPI & 7 & $0 / 7$ & $0.14 \pm 0.4^{* *}$ \\
\hline LC & 7 & $0 / 7$ & $0.29 \pm 0.5^{* *}$ \\
\hline ASA & 7 & $7 / 7$ & $2.71 \pm 1.0^{\star}$ \\
\hline ASA + PPI & 7 & $5 / 7$ & $1.57 \pm 0.8^{*}$ \\
\hline ASA + LC & 7 & $7 / 7$ & $2.57 \pm 0.5^{*}$ \\
\hline
\end{tabular}

$N$ - number of rats in each study group, PPI - proton pump inhibitor, LC - L-carnitine, ASA - acetyl salicylic acid. Values are expressed as mean \pm standard deviation. ${ }^{*} P<0.05$ compared with the control group, ${ }^{* *} p<0.001$ compared with the group given only acetyl salicylic acid.

Table II. Antioxidant enzyme activities and lipid peroxidation levels of the study groups

\begin{tabular}{|lccccc|}
\hline Groups & $\begin{array}{c}\text { CAT } \\
{[\mathrm{kg} / \mathrm{g} \text { protein] }}\end{array}$ & $\begin{array}{c}\text { SOD } \\
{[\mathrm{U} / \mathrm{mg} \text { protein] }}\end{array}$ & $\begin{array}{c}\text { GSH-Px } \\
{[\mathrm{U} / \mathrm{g} \text { protein }]}\end{array}$ & $\begin{array}{c}\text { MDA } \\
{[\mathrm{nmol} / \mathrm{g} \text { protein] }}\end{array}$ & $\begin{array}{c}\text { NO } \\
{[\mu \mathrm{mol} / \mathrm{g} \text { protein] }}\end{array}$ \\
\hline Control & $0.090 \pm 0.02$ & $0.020 \pm 0.004$ & $1.694 \pm 0.37^{\mathrm{b}}$ & $4.387 \pm 1.15^{\mathrm{d}}$ & $0.176 \pm 0.03^{\mathrm{f}}$ \\
\hline PPI & $0.056 \pm 0.02$ & $0.020 \pm 0.002$ & $1.315 \pm 0.23^{\mathrm{b}}$ & $4.606 \pm 1.20^{\mathrm{d}}$ & $0.220 \pm 0.04^{\mathrm{f}}$ \\
\hline LC & $0.057 \pm 0.03$ & $0.021 \pm 0.005$ & $1.176 \pm 0.32^{\mathrm{c}}$ & $3.973 \pm 0.65^{\mathrm{d}}$ & $0.255 \pm 0.06$ \\
\hline ASA & $0.053 \pm 0.02^{\mathrm{a}}$ & $0.017 \pm 0.002$ & $0.827 \pm 0.30^{\mathrm{c}}$ & $6.546 \pm 1.04^{\mathrm{e}}$ & $0.343 \pm 0.08^{\mathrm{g}}$ \\
\hline ASA + PPI & $0.064 \pm 0.02$ & $0.022 \pm 0.004$ & $1.152 \pm 0.23^{\mathrm{c}}$ & $3.945 \pm 0.50^{\mathrm{d}}$ & $0.251 \pm 0.06^{\mathrm{f}}$ \\
\hline ASA + LC & $0.056 \pm 0.02$ & $0.017 \pm 0.004$ & $0.748 \pm 0.18^{\mathrm{c}}$ & $5.318 \pm 1.12$ & $0.279 \pm 0.06^{\mathrm{g}}$ \\
\hline
\end{tabular}

CAT - catalase, SOD - superoxide dismutase, MDA - malondialdehyde, GSH-Px - glutathione peroxidase, NO - nitric oxide, ASA - acetyl salicylic acid group, $A S A+P P I-$ acetyl salicylic acid and proton pump inhibitor group, $L C$ - L-carnitine group, ASA + LC - acetyl salicylic acid and L-carnitine group, PPI - proton pump inhibitor group. Values are expressed as arithmetic mean $\pm S D$. ${ }^{a} p<0.05 \mathrm{vs}$. control group, ${ }^{b} p<0.05$ vs. ASA group, ${ }^{c} p<0.05$ vs. control group, ${ }^{d} p<0.05$ vs. ASA group, ${ }^{e} p<0.05$ vs. control group, ${ }^{f} p<0.05$ vs. ASA group, ${ }^{g} p<0.05$ vs. control group. 


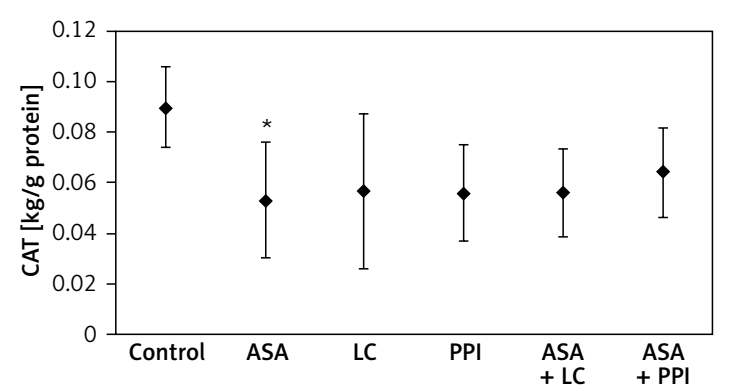

Figure 2. Gastric mucosal catalase activities of the study groups

${ }^{*} P<0.05$ when compared to control group $(n=7$ in each group).

ly $(p=0.204)$, compared to rats that received ASA alone (Table II and Figure 4).

\section{Measurement of NO levels of gastric mucosa}

The NO levels were significantly increased in rats that received ASA alone compared to control and PPI groups ( $p=0.001, p=0.002$, respectively). Administering L-carnitine alone did not alter the NO levels $(p=0.098)$. Pretreatment with PPI (ASA $+\mathrm{PPI})$ significantly reduced NO levels $(p=0.037)$, whereas pretreatment with $\mathrm{L}$-carnitine $(\mathrm{ASA}+\mathrm{LC})$ reduced NO levels insignificantly $(p=0.277)$, compared to rats that received ASA alone (Table II and Figure 5).

\section{Discussion}

Salient findings of the present study are that (a); ASA impaired the gastric mucosal barrier as shown by histopathologic ulcer scores, by reducing the gastric antioxidant enzyme activities (including (AT and GSH-Px) and conversely increasing the products of lipid peroxidation (MDA) and

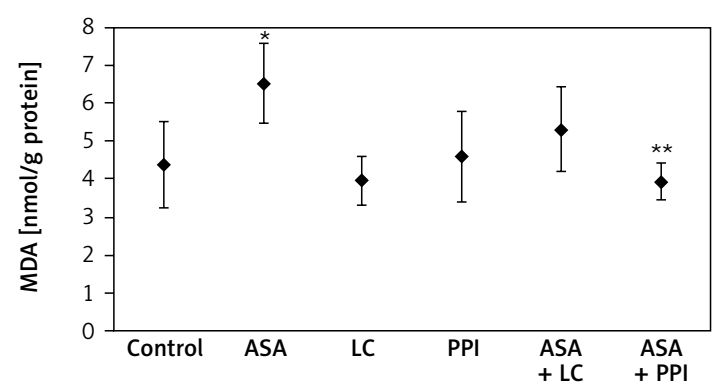

Figure 4. Gastric mucosal malondialdehyde levels of the study groups. Acetyl salicylic acid (ASA) significantly increased MDA levels compared to those in control rats. Pretreatment with a proton pump inhibitor (ASA + PPI) significantly improved MDA levels increased by ASA, but pretreatment with L-carnitine (ASA + LC) did not

${ }^{*} P<0.05$ when compared to control group and ${ }^{* *} p<0.05$ when compared to ASA group, respectively ( $n=7$ in each group).

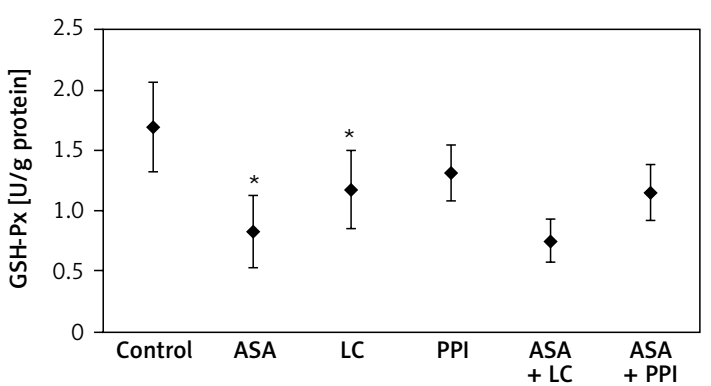

Figure 3. Gastric mucosal glutathione peroxidase activities of the study groups. Administration of acetyl salicylic acid and L-carnitine significantly reduced the GSH-Px activity

${ }^{*} P<0.05$ when compared to the control group $(n=7$ in each group).

NO levels, (b); the administration of L-carnitine did not prevent the occurrence of mucosal lesions; in addition, pretreatment with L-carnitine (ASA + LC) did not improve gastric antioxidant enzyme activities, lipid peroxidation products, or NO levels significantly compared to the ASA group, and (c); gastric tissue MDA and NO levels were significantly lower in the ASA + PPI group than in the ASA group.

The NSAIDs, such as ASA, are known to induce gastric mucosal injury in humans and animals via local and systemic effects [34]. The ASA causes a direct irritant effect by increasing the transport of $\mathrm{H}^{+}$ions, whereas it decreases mucin, surface active phospholipids, bicarbonate secretion, and mucosal proliferation. The ASA also causes damage by formation of free radicals [35]. Lipid peroxidation leads to loss of membrane fluidity and impairment of ion transport and membrane integrity on the surface of epithelial cells and helps to generate gastric lesions [36]. The mechanism by which it causes injury to the gastric mucosa is mainly due to the inhibition of cyclooxygenase and the sup-

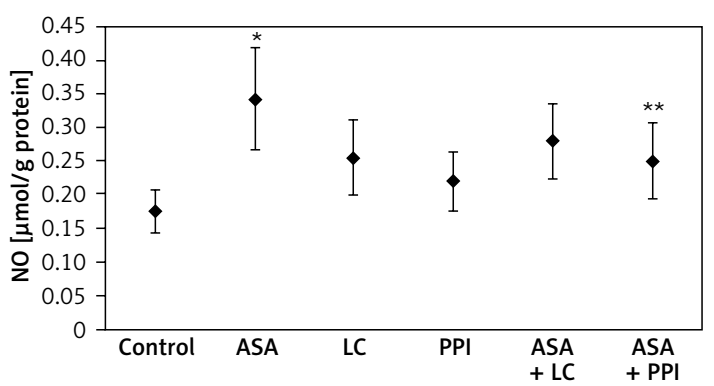

Figure 5. Gastric mucosal nitric oxide (NO) levels of the study groups. Acetyl salicylic acid (ASA) sig nificantly increased NO levels compared to those in control rats. Pretreatment with a proton pump inhibitor (ASA + PPI) significantly improved NO levels increased by ASA, but pretreatment with L-carnitine $(A S A+L C)$ did not

${ }^{\star} P<0.05$ when compared to control group and ${ }^{* *} p<0.05$ when compared to ASA group, respectively ( $n=7$ in each group). 
pression of prostaglandin (PG)-mediated effects on mucosal protection, but the exact pathogenic mechanism remains to be elucidated [37].

The ROS plays a crucial role in the pathogenesis of oxidative damage. In the case of gastric injury, with inflammation and the recruitment of neutrophils by proinflammatory cytokines, the production of ROS is further increased. Gastric mucosal ischemia increases the generation of $\mathrm{OH}^{-}$radicals, which subsequently facilitate the formation of gastric ulcer via cellular antioxidant depletion, lipid peroxidation, and inactivation of gastric peroxidation and protein oxidation [38]. The implication of ROS in gastric mucosal damage was strengthened by the fact that many free radical scavengers, such as ambrex [39], Allophylus serratus [40], and Jasminum grandiflorum [41], provide marked functional and histopathological protection against in vivo ASA-induced gastric mucosal damage. In the present study, pretreatment of rats with PPI partly reduced the histopathological ulcer score, but this was not statistically significant. However, pretreatment with LC had no protective effect on the histopathological ulcer score induced by ASA. Except for SOD, the enzyme activities in gastric tissue were also altered significantly following ASA administration. The CAT and GSH-Px activities were significantly reduced compared to the control values. The ASA administration markedly stimulated lipid peroxidation in gastric tissues, and the MDA content was elevated significantly compared to control rats. In addition, NO levels, an oxidative stress marker, were higher than the control values. These results are in line with the previous reports that demonstrated marked alterations in the enzymatic anti-oxidants following acute administration of ASA to rats $[39,41]$.

$\mathrm{L}$-carnitine and its derivatives prevent the formation of ROS, scavenge free radicals and protect cells from peroxidative stress [20-24]. Two different physiologic mechanisms of L-carnitine have been reported. Firstly, Ronca et al. suggested that $\mathrm{L}$-carnitine inhibits $\mathrm{OH}^{-}$radical production in the Fenton reaction system by chelating iron required for the generation of $\mathrm{OH}^{-}$radicals [42]. Secondly, Di Giacomo et al. showed the preventive effect of L-carnitine on the formation of ROS via the xanthine/XO system [43]. Arafa and Sayed-Ahmed reported that carnitine esters, particularly propionyl L-carnitine, could protect the rat stomach against alcohol-induced injury possibly by its anti-oxidant property [44]. Conversely to its protective effects on gastric mucosa, Valoti et al. have previously reported that L-carnitine derivatives, acetyl L-carnitine and propionyl L-carnitine, stimulated the gastric acid secretion in a dose-dependent manner in vitro and in vivo [45].

Izgut-Uysal et al. suggested that the reducing effect of L-carnitine on gastric damage could be related to the increasing effect on CAT activity in rats following exposure to chronic restraint stress. Pretreatment with carnitine did not change SOD activity, but it increased CAT activity in stressed rats [46]. In our study, only GSH-Px activity was significantly reduced in rats treated with L-carnitine alone, compared to controls. Apart from this, neither PPI nor L-carnitine alone significantly changed the anti-oxidant enzyme activity, compared to control animals. Pretreatment with PPI (PPI + ASA group) or L-carnitine (LC + ASA group), similarly, did not alter the anti-oxidant enzyme status significantly when compared to the ASA group.

Gastric ulcers are also associated with increased lipid peroxidation [47-52]. It has been demonstrated that many pathologic conditions that caused elevation of MDA due to lipid peroxidation were prevented by carnitine and its derivatives, including ischemia/reperfusion injury [53-55], drug-induced cardiomyopathy [56-58], and myocardial infarction $[59,60]$. Izgut-Uysal et al. investigated the gastroprotective effects of L-carnitine in a cold-restraint stress (CRS) rat model. They reported that pretreatment with L-carnitine $50 \mathrm{mg} /$ $\mathrm{kg}$ per day for 10 days reduced the products of lipid peroxidation as well as increasing CAT activity in both blood and gastric mucosa [21]. More recently, Dokmeci et al. demonstrated that L-carnitine significantly reduced the area of mucosal lesions induced by ethanol starting at a dose of $50 \mathrm{mg} / \mathrm{kg}$, with the maximum effect at a dose of $500 \mathrm{mg} / \mathrm{kg}$. They also observed that pretreatment with high dose LC $(500 \mathrm{mg} / \mathrm{kg})$ not only inhibited thiobarbituric acid reactive substances in the plasma and gastric mucosa, but also prevented the ethanol-induced reduction of gastric GSH [25]. In our study, pretreatment with PPI significantly reduced the MDA levels in rat stomach compared to animals given ASA alone, whereas pretreatment with L-carnitine did not alter MDA levels in comparison to rats that received only ASA. We treated the rats with $50 \mathrm{mg} / \mathrm{kg}$ L-carnitine for 21 days. In addition, $1 \mathrm{~h}$ before the administration of ASA, they were treated with a single high dose of L-carnitine (375 $\mathrm{mg} / \mathrm{kg}$ ), similar to Dokmeci et al. [25]. Izgut-Uysal et al. also reported a protective effect of L-carnitine on CRS exposed rats at concentrations of more than $50 \mathrm{mg} / \mathrm{kg}$ per day. However, no significantly different effect was observed between 50 and $100 \mathrm{mg} / \mathrm{kg}$ per day of L-carnitine [21]. More recently, like in our study, Izgut-Uysal et al. used L-carnitine $(50 \mathrm{mg} / \mathrm{kg}$ ) for 21 days in Wistar rats with chronic restraint stress-induced gastric mucosal injury; the authors reported that L-carnitine treatment prevented the stress-induced increase in the lesion index and lipid peroxidation, and improved the $\mathrm{PGE}_{2}$ and mucus content in gastric mucosa [46]. Therefore, we consider that the failure 
of L-carnitine treatment in our study should not be attributed only to the L-carnitine dosage.

Prostaglandins play an important role in the prevention of gastric mucosal injury. Among PGs, $\mathrm{PGE}_{1}, \mathrm{PGE}_{2}$, and $\mathrm{PGI}_{2 \alpha}$ have been shown to prevent gastric mucosal injury induced by various noxious stimuli $[61,62]$. Especially, $\mathrm{PGI}_{2}$ and $\mathrm{PGE}_{2}$ are wellknown protectors of the gastric mucosa. A reduction of these compounds leads to decreases in mucus synthesis and mucosal blood flow resulting in the susceptibility of gastric mucosa to gastric acid and noxious factors [63]. Izgut-Uysal et al. suggested that L-carnitine might have prevented gastric mucus depletion by increasing mucosal PGE in the CRS group since $\mathrm{PGE}_{2}$ is important in mucus production [21]. In our study, we were unable to detect the changes in acidic mucopolysaccharide or $\mathrm{PGE}_{2}$ content of the gastric mucosa. However the findings of Garrelds et al. where there was no detectable changes in $\mathrm{PGE}_{2}$ content with short(300 mg/kg) and long-term (50 mg/kg) feeding of L-carnitine and congeners on the production of eicosanoids from rat peritoneal leukocytes [64] may, at least partly, support our negative results with L-carnitine in rats exposed to ASA.

The NO released from vascular epithelium, epithelial cells of the gastrointestinal tract and sensory nerves can influence many of the same components of mucosal defense as do PGs. Synthetic analogues of lipoxins as well as the newer class of NSAIDs releasing NO may be used in the future as the therapeutic approach to counteract adverse effects in the stomach associated with NSAID ingestion [37]. In the present study, pretreatment with PPI significantly reduced the NO levels in rat stomach compared to animals given ASA alone. However, pretreatment with L-carnitine did not affect the NO levels in comparison with rats exposed to only ASA.

Neutrophil and oxygen radical-dependent microvascular injuries may also be important prime events that lead to mucosal injury induced by NSAIDs [65]. Lipid peroxidation mediated by oxygen radicals, especially hydroxyl radicals, plays a crucial role in the development of the gastric mucosal injury induced by indomethacin [66]. A single intragastric administration of L-carnitine at various doses $(10,50,100 \mathrm{mg} / \mathrm{kg})$ significantly prevented indomethacin-induced gastric mucosal injury in rats and decreased the ulcer index macroscopically and histopathologically [26]. In an ischemia-reperfusion injury model, L-carnitine $100 \mathrm{mg} / \mathrm{kg}$ significantly reduced both the gastric injury and myeloperoxidase activity, which is an important index of neutrophil accumulation [65].

Carnitine deficiency led to severe gut injury accompanied by a severe immune phenotype and pro-inflammatory status in OCTN2 (SLC22A5) carnitine transporter (-/-) newborn mice [67]. Very recently a significant impairment in the $\beta$-oxidation pathway was reported in mucosal biopsies of 26 patients with active ulcerative colitis. The administration of carnitine, either alone or in combination with ATP, did not improve Na-butyrate metabolism [68]. However, in a rat model of 2,4,6-trinitrobenzenesulfonic acid-induced acute and reactivated colitis, oral and intrarectal propionyl L-carnitine (but not L-carnitine or propionate) was shown to be effective in reducing intestinal mucosal inflammation, endothelial dysfunction, and oxidative stress induced by ROS [69]. And finally, coadministration of intraperitoneal L-carnitine played a major protective role in radiation-induced ileal $(100$ mg/kg/day was better than 200 mg/ $\mathrm{kg} /$ day) and colonic (300 ml/kg) rat mucosal injury $[70,71]$.

The bioavailability of L-carnitine decreased from $100 \%$ to $42 \%$ with an increase in dose in a rat model of Gl disposition. This dose-dependent alteration in the $\mathrm{Gl}$ absorption of L-carnitine was attributed to its physiologic intestinal transport-based mechanism [72]. After oral administration, the small intestine is the major site of L-carnitine absorption without a first-pass degradation effect, whereas its absorption in the cecum and the colorectal sites is negligible [73]. Taken together, not only the dose intensity, but also the complex kinetic physiological mechanisms including absorption site, gastric emptying rate [72], and other intestinal transport dynamics may, at least partly, play a role in the gastroprotective roles of L-carnitine in gastric injury models. In our gastric injury model, the mucosal injury of the small intestine in addition to gastric tissue might have been related to the ineffectiveness of L-carnitine treatment.

In conclusion, taken together, gastroprotective effects of L-carnitine have been shown in some conditions via oxidative stress and lipid peroxidation. Although the anti-oxidant and/or free radical scavenging mechanism of L-carnitine remains unclear, the results of the present study indicate that L-carnitine did not prevent gastric mucosal injury induced by ASA histopathologically or in terms of oxidative reactions. Hence, further comprehensive studies may elucidate the other mechanisms involved in the anti-ulcer effect of L-carnitine treatment.

\section{Acknowledgments}

Chemical compounds studied in this article: L-carnitine hydrochloride, synthetic, $\geq 98 \%$ [(-)-beta-hydroxy-gamma-(trimethylammonio) butyrate] [PubChem CID: 656657 (6645-46-1)].

This work is supported by the Scientific Research Fund of Fatih University under project number P-53010801-1. 


\section{Conflict of interest}

The authors declare no conflict of interest.

\section{References}

1. Sostres C, Gargallo CJ, Arroyo MT, Lanas A. Adverse effects of non-steroidal anti-inflammatory drugs (NSAIDs, aspirin and coxibs) on upper gastrointestinal tract. Best Pract Res Clin Gastroenterol 2010; 24: 121-32.

2. Pohle T, Brzozowski T, Becker JC, et al. Role of reactive oxygen metabolites in aspirin-induced gastric damage in humans: gastroprotection by vitamin C. Aliment Pharmacol Ther 2001; 15: 677-87.

3. Hiraishi H, Shimada T, Ivey KJ, Terano A. Role of antioxidant defenses against ethanol-induced damage in cultured rat gastric epithelial cells. J Pharmacol Exp Ther 1999; 289: 103-9.

4. Zimmerman BJ, Grisham MB, Granger DN. Role of oxidants in ischemia/reperfusion-induced granulocyte infiltration. Am J Physiol Gastrointest Liver Physiol 1990; 258: $185-90$.

5. Matthews GM, Butler RN. Cellular mucosal defense during Helicobacter pylori infection: a review of the role of glutathione and the oxidative pentose pathway. Helicobacter 2005; 10: 298-306.

6. Das D, Bandyopadhyay D, Bhattacharjee M, Banerjee RK. Hydroxyl radical is the major causative factor in stress-induced gastric ulceration. Free Radic Biol Med 1997; 23: 8-18.

7. Grisham MB, Granger DN. Neutrophil-mediated mucosal injury: role of reactive oxygen metabolites. Dig Dis Sci 1988; 33: 6-15.

8. Ligumsky M, Klar A, Siguencia J, Arnon R, Gati I, Kohen R. Changes in reducing power profile of gastric juice in patients with active duodenal ulcer. Biomed Pharmacoth er 2005; 59: 345-50.

9. Rebouche CJ, Paulson DJ. Carnitine metabolism and function in humans. Annu Rev Nutr 1986; 6: 41-66.

10. Roe CR, Millington DS, Maltby DA, Bohan TP, Hoppel CL. L-Carnitine enhances excretion of propionyl coenzyme A as propionylcarnitine in propionic academia. J Clin Invest 1984; 73: 1785-8.

11. Gulewitsch W, Krimberg R. Zur Kenntnis der Extraktivstoffe der Muskeln. II. Mitteilung. Uber das Carnitin. Hoppe-Seyler's Z Physiol Chem 1905; 45: 326-30.

12. Tomita M, Sendju Y. Uber die Oxyaminoverbindungen, welche die Biuretreaktion ziegen. III. Spaltung der $\mathrm{m}$-amino-b-oxybuttersaure in die optisch-aktiven Komponenten. Hoppe-Seyler's Z Physiol Chem 1927; 169: 263-77.

13. Rebouche CJ, Seim H. Carnitine metabolism and its regulation in microorganisms and mammals. Ann Rev Nutr 1998; 18: 39-61.

14. Savica V, Calvani M, Benatti P, et al. Carnitine system in uremic patients: molecular and clinical aspects. Semin Nephrol 2004; 24: 464-8.

15. Evans A. Dialysis-related carnitine disorder and levocarnitine pharmacology. Am J Kidney Dis 2003; 41: 13-26.

16. Famularo G, Matricardi F, Nucera E, Santini G, De Simone C. Carnitine deficiency: primary and secondary syndromes. In: Carnitine Today. De Simone C, Famularo G (eds). Landes Bioscience, Austin, TX 1997; 119-61.

17. Pepine CJ. The therapeutic potential of carnitine in cardiovascular disorders. Clin Ther 1991; 13: 2-21.

18. Goa KL, Brogden RN. L-Carnitine. A preliminary review of its pharmacokinetics, and its therapeutic use in isch- aemic cardiac disease and primary and secondary carnitine deficiencies in relationship to its role in fatty acid metabolism. Drugs 1987; 34: 1-24.

19. Ahmad S. L-Carnitine in dialysis patients. Semin Dial 2001; 14: 209-17.

20. Arockia Rani PJ, Panneerselvam C. Carnitine as a free radical scavenger in aging. Exp Gerontol 2001; 36: 1713-26.

21. Izgut-Uysal VN, Agac A, Derin N. Effect of carnitine on stress-induced lipid peroxidation in rat gastric mucosa. J Gastroenterol 2001; 36: 231-6.

22. Luo X, Reichetzer B, Trines J, Benson LN, Lehotay DC. L-carnitine attenuates doxorubicin-induced lipid peroxidation in rats. Free Radic Biol Med 1999; 26: 1158-65.

23. Packer L, Valenza M, Serbinova E, Starke-Reed P, Frost K, Kagan V. Free radical scavenging is involved in the protective effect of L-propionyl-carnitine against ischemia-reperfusion injury of the heart. Arch Biochem Biophys 1991 ; 288: 533-7.

24. Sener G, Paskaloglu K, Satiroglu H, Alican I, Kaçmaz A, Sakarcan A. L-carnitine ameliorates oxidative damage due to chronic renal failure in rats. J Cardiovasc Pharmacol 2004; 43: 698-705.

25. Dokmeci D, Akpolat M, Aydogdu N, Doganay L, Turan FN. L-carnitine inhibits ethanol-induced gastric mucosal injury in rats. Pharmacol Rep 2005; 57: 481-8.

26. Erkin B, Dokmeci D, Altaner S, Turan FN. Gastroprotective effect of L-carnitine on indomethacin-induced gastric mucosal injury in rats: a preliminary study. Folia Med (Plovdiv) 2006; 48: 86-9.

27. Melchiorri D, Sewerynek E, Reiter RJ, Ortiz GG, Poeggeler B, Nisticò G. Suppressive effect of melatonin administration on ethanol-induced gastroduodenal injury in rats in vivo. Br J Pharmacol 1997; 121: 264-70.

28. Sun Y, Oberley LW, Li Y. A simple method for clinical assay of superoxide dismutase. Clin Chem 1988; 34: 497-500.

29. Aebi H. Catalase. In: Methods of Enzymatic Analysis. Bergmeyer HU (ed.). Academic Press, New York and London 1974; 673-7.

30. Paglia DE, Valentine WN. Studies on the quantitative and qualitative characterization of erythrocyte glutathione peroxidase. J Lab Clin Med 1967; 70: 158-69.

31. Draper HH, Hadley M. Malondialdehyde determination as index of lipid peroxidation. Meth Enzymol 1990; 186: 421-31.

32. Lowry OH, Rosebrough NJ, Farr AL, Randall RJ. Protein measurement with the Folin phenol reagent. J Biol Chem 1951; 193: 265-75.

33. Cortas NK, Wakid NW. Determination of inorganic nitrate in serum and urine by a kinetic cadmium-reduction method. Clin Chem 1990; 36: 1440-3.

34. Alvarez A, Pomar F, Sevilla, Montero MJ. Gastric antisecretory and antiulcer activities of an ethanolic extract of Bidens pilosa L. var. radiata Schult. Bip J Ethnopharmacol 1999; 67: 333-40.

35. Scheiman JM. NSAIDs, eicosonoids, and the gastroenteric tract. Gastroenterol Clin North Am 1996; 25: 279-98.

36. Bandyopadhyay U, Das D, Bandyopadhyay D, Bhattacharjee $M$, Banerjee RK. Role of reactive oxygen species in mercaptomethylimidazole-induced gastric acid secretion and stress-induced gastric ulceration. Curr Sci 1999; 76: 55-63.

37. Pajdo R, Brzozowski T, Szlachcic A, et al. Lipoxins, the novel mediators of gastroprotection and gastric adaptation to ulcerogenic action of aspirin. Curr Pharm Des 2011; 17: 1541-51.

38. Dong MH, Kaunitz JD. Gastroduodenal mucosal defence. Curr Opin Gastroenterol 2006; 22: 599-606. 
39. Jainu M, Devi CS. Effect of ambrex (an amber based formulation) on gastric mucosal damage: role of antioxidant enzymes and lipid profile. Indian J Physiol Pharmacol 2004; 48: 343-7.

40. Dharmani P, Mishra PK, Maurya R, Singh Chauhan V, Palit G. Allophylus serratus: a plant with potential anti-ulcerogenic activity. J Ethnopharmacol 2005; 99: 361-6.

41. Umamaheswari M, Asokkumar K, Rathidevi R, Sivashanmugam AT, Subhadradevi V, Ravi TK. Antiulcer and in vitro antioxidant activities of Jasminum grandiflorum $\mathrm{L}$. J Ethnopharmacol 2007; 110: 464-70.

42. Ronca G, Ronca F, Yu G, Zucchi R, Bertelli A. Protection of isolated perfused working rat heart from oxidative stress by exogenous L-propionyl carnitine. Drugs Exp Clin Res 1992; 18: 475-80.

43. Di Giacomo C, Latteri F, Fichera C, et al. Effect of acetyl-L-carnitine on lipid peroxidation and xanthine oxidase activity in rat skeletal muscle. Neurochem Res 1993; 18: 1157-62.

44. Arafa HM, Sayed-Ahmed MM. Protective role of carnitine esters against alcohol-induced gastric lesions in rats. Pharmacol Res 2003; 48: 285-90.

45. Valoti M, Benocci A, Marazova K, Mantovani P. Effects of carnitine and its derivatives on gastric acid secretion in rats. Pharmacol Res 1996; 34: 219-24.

46. Izgut-Uysal VN, Bülbül M, Tan R, et al. Effect of chronic stress and L-carnitine on rat stomach. J Physiol Sci 2007; 57: 187-92.

47. Bandyopadhyay D, Biswas K, Bhattacharyya M, Reiter RJ, Banerjee RK. Involvement of reactive oxygen species in gastric ulceration: protection by melatonin. Indian J Exp Biol 2002; 40: 693-705.

48. Khosla P, Karan RS, Bhargava VK. Effect of garlic oil on ethanol induced gastric ulcers in rats. Phytother Res 2004; 18: 87-91.

49. Naito Y, Yoshikawa T, Matsuyama K, et al. Effects of oxygen radical scavengers on the quality of gastric ulcer healing in rats. J Clin Gastroenterol 1995; 21: 82-6.

50. Oates PJ, Hakkinen JP. Studies on the mechanism of ethanol-induced gastric damage in the rat. Gastroenterology 1988; 94: 10-21.

51. Robert A, Lancaster C, Davis JP, Field SO, Sinha AJ, Thornburgh BA. Cytoprotection by prostaglandin occurs in spite of penetration of absolute ethanol into the gastric mucosa. Gastroenterology 1985; 88: 328-33.

52. Mizui T, Doteuchi M. Lipid peroxidation. A possible role in gastric damage induced by ethanol in rats. Life Sci 1986; 38: 2163-7.

53. Akgun S, Tekeli A, Kurtkaya O, et al. Neuroprotective effects of FK-506, L-carnitine and azathioprine on spinal cord ischemia-reperfusion injury. Eur J Cardiothorac Surg 2004; 25: 105-10.

54. Kocer I, Kulacoglu D, Altuntas I, Gundogdu C, Gullulu G. Protection of the retina from ischemia-reperfusion injury by L-carnitine in guinea pigs. Eur J Ophthalmol 2003; 13: 80-5.

55. Loster H, Bohm U. L-carnitine reduces malondialdehyde concentrations in isolated rat hearts in dependence on perfusion conditions. Mol Cell Biochem 2001; 217: 83-90.

56. Kawasaki N, Lee JD, Shimizu H, Ueda T. Long-term L-carnitine treatment prolongs the survival in rats with adriamycin-induced heart failure. J Card Fail 1996; 2: 293-9.

57. Sayed-Ahmed MM, Salman TM, Gaballah HE, Abou El-Naga SA, Nicolai R, Calvani M. Propionyl-L-carnitine as protector against adriamycin-induced cardiomyopathy. Pharmacol Res 2001; 43: 513-20.
58. Sayed-Ahmed MM, Shaarawy S, Shouman SA, Osman AM. Reversal of doxorubicin-induced cardiac metabolic damage by L-carnitine. Pharmacol Res 1999; 39: 289-95.

59. Pauly DF, Pepine CJ. The role of carnitine in myocardial dysfunction. Am J Kidney Dis 2003; 41: 35-43.

60. Singh RB, Niaz MA, Agarwal P, Beegum R, Rastogi SS, Sachan DS. A randomized, double-blind, placebo controlled trial of L-carnitine in suspected acute myocardial infarction. Postgrad Med J 1996; 72: 45-50.

61. Auguste L, Sterman HR, Stein TA, Bailey B, Wise L. Effect of verapamil on the gastric mucosal level of PGE2 during stress. J Surg Res 1990; 49: 34-6.

62. Victor BE, Schmidt KL, Smith GS, Reed RL, Thompson DA, Miller TA. Prostaglandin-induced gastric mucosal protection against stress injury. Absence of a relationship to tissue glutathione levels. Ann Surg 1989; 209: 289-96.

63. Takezono Y, Joh T, Oshima T, et al. Role of prostaglandins in maintaining gastric mucus-cell permeability against acid exposure. J Lab Clin Med 2004; 143: 52-8.

64. Garrelds IM, Elliott GR, Zijlstra FJ, Bonta IL. Effects of short and long term feeding of l-carnitine and congeners on the production of eicosanoids from rat peritoneal leucocytes. Br J Nutr 1994; 72: 785-93.

65. Derin N, Agac A, Bayram Z, Asar M, Izgut-Uysal VN. Effects of L-carnitine on neutrophil-mediated ischemia-reperfusion injury in rat stomach. Cell Biochem Funct 2006; 24: 437-42.

66. Naito Y, Yoshikawa T, Yoshida N, Kondo M. Role of oxygen radical and lipid peroxidation in indomethacin-induced gastric mucosal injury. Dig Dis Sci 1998; 43: 30-4.

67. Sonne S, Shekhawat PS, Matern D, Ganapathy V, Ignatowicz L. Carnitine deficiency in OCTN2-/- newborn mice leads to a severe gut and immune phenotype with widespread atrophy, apoptosis and a pro-inflammatory response. PLoS One 2012; 7: e47729.

68. De Preter V, Geboes KP, Bulteel V, et al. Kinetics of butyrate metabolism in the normal colon and in ulcerative colitis: the effects of substrate concentration and carnitine on the beta-oxidation pathway. Aliment Pharmacol Ther 2011; 34: 526-32.

69. Scioli MG, Stasi MA, Passeri D, et al. Propionyl-L-carnitine is efficacious in ulcerative colitis through its action on the immune function and microvasculature. Clin Transl Gastroenterol 2014; 5: e55.

70. Akpolat M, Gulle K, Topcu-Tarladacalisir Y, et al. Protection by $L$-carnitine against radiation-induced ileal mucosal injury in the rat: pattern of oxidative stress, apoptosis and cytokines. Int J Radiat Biol 2013; 89: 732-40.

71. Tas S, Ozkan OF, Cikman O, Kiraz A, Akgun Y, Karaayvaz $M$. L-carnitine has a protective effect on the colonic mucosa during abdominopelvic radiotherapy in rats. Acta Cir Bras 2016; 31: 615-20.

72. Matsuda K, Yuasa H, Watanabe J. Physiological mechanism-based analysis of dose-dependent gastrointestinal absorption of L-carnitine in rats. Biopharm Drug Dispos 1998; 19: 465-72.

73. Matsuda K, Yuasa H, Watanabe J. Fractional absorption of L-carnitine after oral administration in rats: evaluation of absorption site and dose dependency. Biol Pharm Bull 1998; 21: 752-5. 